\title{
5-year experience with vulval lesions in a tertiary care hospital: series of 115 cases
}

\author{
Ritu Bhat*, Sachin Kolte
}

Department of Pathology, Vardhman Mahavir Medical College and Safdarjung Hospital, Ansari Nagar, New Delhi, India

\author{
Received: 25 September 2020 \\ Revised: 31 October 2020 \\ Accepted: 02 November 2020 \\ *Correspondence: \\ Dr. Ritu Bhat, \\ E-mail: rabbi929@gmail.com
}

Copyright: ( $)$ the author(s), publisher and licensee Medip Academy. This is an open-access article distributed under the terms of the Creative Commons Attribution Non-Commercial License, which permits unrestricted non-commercial use, distribution, and reproduction in any medium, provided the original work is properly cited.

\begin{abstract}
Background: Wide range of vulval lesions have been described with similar modes of presentation. Benign and inflammatory lesions form the major chunk. Squamous cell carcinoma is the most reported malignant entity. Aim was to review the vulval lesions received in our department

Methods: We studied the data from the archives of the Department of Pathology for a period of 5 years from January 2014 to December 2018 for vulval biopsies and specimens sent for histopathological examination. The final diagnoses were divided into non-neoplastic, neoplastic and non- specific.

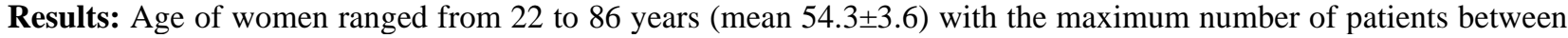
50 to 60 years of age. Most common form of clinical presentation was an itchy white elevated lesion on the vulva (72 cases, 62.6\%). The most common site for the lesions was labia minora (90 cases, $78.2 \%$ ). Non neoplastic lesions were seen in 53 cases and neoplastic lesions were seen in 52 cases. There were $28(53.8 \%)$ benign lesions while 24 cases (46.1\%) were malignant. Squamous cell carcinoma was the most frequently diagnosed form accounting for 20 cases (83.3\%). Rare tumours like Malignant melanoma, Merkel cell carcinoma and Neuroendocrine carcinoma formed $16.6 \%(n=4)$. Seven cases were premalignant. Two cases had non-specific histologic diagnosis showing mild chronic inflammation.

Conclusions: Previous studies have reported that non-neoplastic lesions form around $70 \%$ of cases. However, in our study we found that the non-neoplastic and neoplastic lesions form equal number of cases (46\%) which may be attributed to increased awareness or geographical variation.
\end{abstract}

Keywords: Vulval lesions, Squamous cell carcinoma, Neuroendocrine carcinoma, Malignant melanoma

\section{INTRODUCTION}

A large number of vulval lesions have been reported ranging from mild inflammation and dystrophy to frank carcinoma with considerable overlap in symptoms. The lesions may be exacerbated due to variations in personal hygiene, high risk behaviour, cultural and societal norms. ${ }^{1}$ There is a predilection for neoplastic lesions especially malignancies amongst post-menopausal women. $^{2}$
The vulvo-vaginal region is formed by the close approximation of all the three embryological layers viz. cloacal endoderm, paramesonephric mesoderm and urogenital ectoderm. ${ }^{3}$ All of these derivatives differ in their structure along with their response to different stimuli like hormones, immunity and systemic disorders. ${ }^{4}$ Underlying neuro-vascular structures also modify these aspects. Different epithelia, from keratinized squamous epithelium to squamous mucosa, cover the vulva. ${ }^{3}$ This leads to a wide spectrum of vulval lesions with nonspecific symptoms. Any component like squamous 
epithelium, pilosebaceous units, sweat glands, muscle, deeper glands or neurovascular structures could be affected in vulval lesions. ${ }^{5}$

The general approach for evaluation of vulval lesions includes history, clinical examination and investigations. Clinical suspicions for malignancy typically arise when features like asymmetry, border irregularity, colour variation, rapid changes or non-healing lesions are present. ${ }^{6}$ However, the clinical features may change over time. Thus, it is often difficult to differentiate between non-neoplastic and neoplastic lesions based on clinical grounds alone. Hence, biopsy and histo-pathological examination is essential for correct and rapid diagnosis. ${ }^{6}$

This study is undertaken to evaluate the vulval specimens received in our department, categorize them and compare our findings with previous studies.

\section{METHODS}

The current retrospective study was done by compiling data from the archives of our department over a period of five years from January 2014 to December 2018. The data assessed included patient's age, chief complaint, site of lesions, menstrual history and final diagnosis. The diagnoses were classified into non-neoplastic, benign, malignant, premalignant and non-specific. Our search yielded 117 biopsies and 3 vulvectomy specimens from 115 patients. In two cases, repeat biopsies were received. In three cases biopsies were followed by vulvectomy.

In 32 cases the pertinent clinical details like chief complaint and the exact site of lesion were not mentioned in the histopathology requisition form.

The specimens were processed and formalin-fixed paraffin embedded sections were stained with routine hematoxylin and eosin. Serial sections, deep cuts, special stains and immunohistochemistry were performed wherever required.

\section{RESULTS}

The age of the women ranged from 22 to 86 years (Table 1) (mean 54.3 years). Maximum number patients were post-menopausal between the ages of 50 to 60 years. The most common chief complaint was an itchy white elevated lesion (Table 2) (72 cases, 62.6\%) followed by itching (19 cases, 16.5\%); other chief complaints being redness, ulcer and discharge. The most common site of lesion was labia minora (90 cases, 78.2\%) followed by labia majora (21 cases, $18.2 \%$ ). In one case, multiple biopsies were received from the labia minora, fourchette and vestibule.

The final diagnoses of vulval lesions from 115 women who underwent biopsies is summarised in (Table 3 ).
Lichen sclerosus was the most common non-neoplastic lesion (18 cases, 15.6\%) followed by lichen planus (Figure 1) (12 cases, 10.4\%). Microscopic examination showed thinned out epidermis, loss of rete ridges, subepidermal band-like lymphocytic infiltrate and dermal hyalinisation. Cystic lesions included epidermal inclusion cyst (8 cases, $6.9 \%$ ) followed by mucous cyst showing columnar lining with mucin ( 5 cases, $4.3 \%$ ). Other cystic lesions included bartholins cyst (2 cases, 1.7\%) and gartner cyst (1 case, $0.8 \%$ ).

Table 1: Age distribution of women with vulval lesions $(n=115)$.

\begin{tabular}{|ll|}
\hline Age groups (years) & Number \\
\hline $\mathbf{2 0 - 3 0}$ & 11 \\
\hline $\mathbf{3 0 - 4 0}$ & 17 \\
\hline $\mathbf{4 0 - 5 0}$ & 16 \\
\hline $\mathbf{5 0 - 6 0}$ & 36 \\
\hline $\mathbf{6 0 - 7 0}$ & 14 \\
\hline $\mathbf{7 0 - 8 0}$ & 15 \\
\hline $\mathbf{8 0 - 9 0}$ & 5 \\
\hline
\end{tabular}
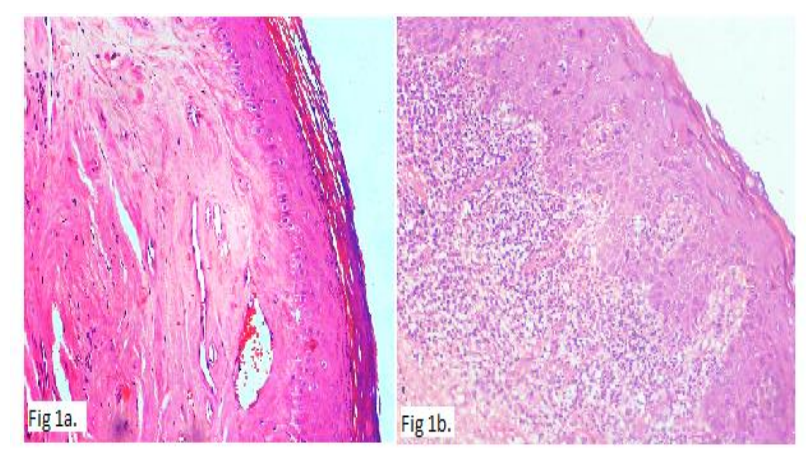

Figure 1: (a) Lichen sclerosus (H\&E; 20X) (b) Lichen planus (H\&E; 40X).

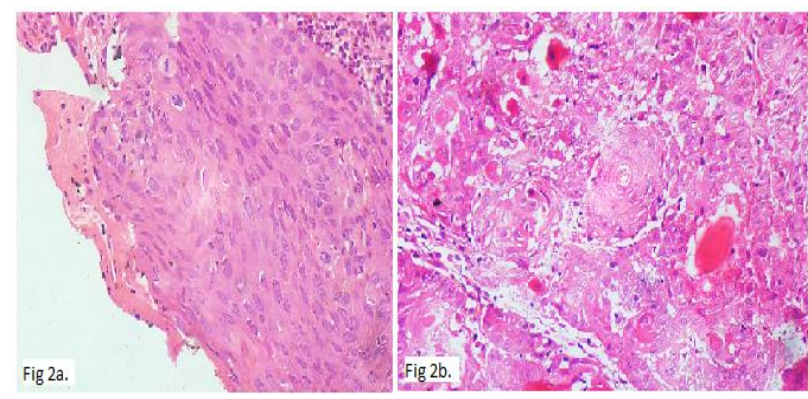

Figure 2: (a) Vulval intraepithelial neoplasia grade III (H\&E; 40X) (b) Well differentiated squamous cell carcinoma $(\mathrm{H} \& \mathrm{E} ; 40 \mathrm{X})$.

Squamous papillomas were the most common benign neoplastic lesion accounting for 14 cases (12.1\%) followed by fibro-epithelial polyp (6 cases, $8.6 \%$ ) showing fibro-vascular stalk covered with keratinised stratified squamous epithelium. One case of leiomyoma with myxoid change $(0.8 \%)$ and one case of neurofibroma $(0.8 \%)$ was also seen. 
Table 1: Histopathological diagnosis in vulval lesions.

\begin{tabular}{|c|c|c|c|}
\hline Non-Neoplastic (n=52) & Benign ( $n=22)$ & Premalignant $(n=7)$ & Malignant $(n=24)$ \\
\hline Lichen Sclerosus (18) & Squamous papilloma (14) & Condyloma acuminatum (2) & $\begin{array}{l}\text { Squamous cell carcinoma } \\
(20)\end{array}$ \\
\hline Lichen Planus (12) & Fibroepithelial polyp (6) & $\begin{array}{l}\text { Vulval intraepithelial } \\
\text { neoplasia (5) }\end{array}$ & Malignant melanoma (2) \\
\hline Bartholins cyst (2) & Leiomyoma (1) & & Merkel cell carcinoma (1) \\
\hline Gartner cyst (1) & Neurofibroma (1) & & Neuroendocrine tumour (1) \\
\hline \multicolumn{4}{|c|}{ Nabothian cyst (5) } \\
\hline \multicolumn{4}{|c|}{ Epidermal inclusion cyst (8) } \\
\hline \multicolumn{4}{|c|}{ Mucous cyst (5) } \\
\hline Plasma cell vulvitis (1) & & & \\
\hline
\end{tabular}

Two cases of condyloma acuminatum (1.6\%) were diagnosed showing hyperkeratosis, acanthosis and koilocytic changes. Five cases of vulval intraepithelial neoplasia (4.3\%) were seen (Figure 2) with one case showing full thickness dysplasia.

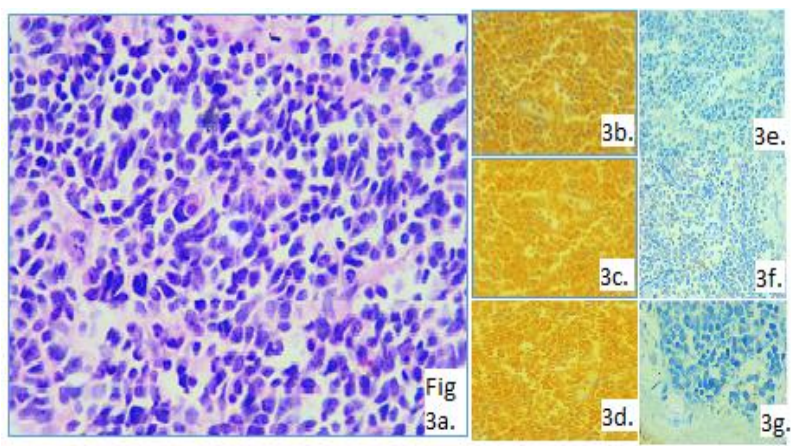

Figure 3: (a) neuroendocrine tumour (H\&E; 40X); (b) synaptophysin; (c) chromogranin; (d) NSE; (e) LCA (f) EMA (g) P63.

Squamous cell carcinoma was diagnosed in 20 cases (17\%). Two cases of squamous cell carcinoma were followed by vulvectomy after diagnosis on biopsy. Rarer neoplasms included one case of merkel cell carcinoma $(0.8 \%)$, one case of neuroendocrine tumour (0.8\%) showing sheets of small round cells with nuclei having salt and pepper chromatin (Figure 3) and two cases of malignant melanoma (1.6\%) were also reported.

Total 10 cases were non-specific showing mild chronic inflammation and one case of plasma cell vulvitis was seen.

\section{DISCUSSION}

Vulval lesions require the expertise of both gynaecologist and the pathologist. ${ }^{7}$

Most of the studies have emphasized the role of vulval biopsies for rapid and correct diagnosis. ${ }^{8,9}$ To achieve this, ample biopsies from prudent locations should be taken. ${ }^{1}$ Gynaecologists can take the help of toluidine blue and acetic acid to take proper biopsies. ${ }^{10}$

Our study was one of the largest studies from India, which included a wide range of adults who were mostly post-menopausal which is the usual pattern. ${ }^{11}$ Pruritis is the most commonly reported symptom of vulval lesions and labia majora is the most common site of lesion in previous studies. ${ }^{1,6}$ In our study the most common chief complaint was itchy elevated plaque and the most common site of lesion was labia minora. Of the 115 cases, 112 cases had a definitive diagnosis. Only 2 cases were diagnosed as non-specific. The most common nonneoplastic lesion was lichen sclerosus (18 cases, $15.6 \%)$. Vulval intra-epithelial neoplasia (VIN) was the most common premalignant lesion accounting for 5 cases (4.3\%) including one case of full thickness dysplasia. They are graded from 1 to 3 based on the extent of epithelial involvement however, this grading by no means depicts a continuum. ${ }^{12,13}$ The distinction between VIN and invasive squamous cell carcinoma can only be done on histopathology. ${ }^{12}$

Total $83.3 \%$ of malignancies (20 cases) were of Squamous cell carcinoma. Previous studies have reported $90 \%$ of all vulval cancers are squamous cell carcinoma. ${ }^{14,15}$

Rarer cancers like malignant melanoma, neuroendocrine tumour and merkel cell carcinoma accounted for $16.6 \%$ of malignancies. Previous studies have quoted much lower figures. . $^{1,6}$

Neoplastic and non-neoplastic lesions were equal in proportion $(46 \%)$. Previous studies in India have reported lower figures for neoplastic lesions (29\%). ${ }^{1,6}$ There was a higher prevalence of neoplastic lesions among postmenopausal women who accounted for 39 cases out of 52 $(75 \%)$.

Verrucous carcinomas are seen in less than $1 \%$ of cases. ${ }^{14}$ There were no cases of verrucous carcinoma, adenocarcinoma or micro-invasive squamous cell carcinoma. 
The study conducted by Ozdemir et al is one of the largest recent studies in Asia on vulval lesions comprising a total of 263 cases. The mean age of the women was 46.27 years with maximum number of patients from Ankara in the age group 41-50 years which was lower than our study. The most common clinical presentation was itching and the most common site of lesion was labia majora. They also reported a higher number of non-neoplastic lesions which accounted for $65.4 \%$ of the cases. Even amongst neoplasms benign lesions were more common accounting for $30.8 \%$ while the malignant lesions comprised about $3.8 \%$ which was starkly different from our study.

In India, a similar study was conducted in 2014 by Mohan et al. which included 170 cases. The women included were younger than in our study and the mean age of women was 38.2 years and most of them belonged to the age group 31-40 years. The most common complaint was itching and the most common site of lesion was labia majora. Non- neoplastic lesions were more common accounting for $55.29 \%$ of cases. However, the malignant and premalignant lesions were more common comprising $54 \%$ of neoplasms. In $15.2 \%$ of cases no specific histologic diagnosis was rendered.

Another study from India including 55 cases was conducted by Mohan et al. The majority of women were post-menopausal with maximum number of cases in the age group 45-55 years. The most common symptom was itching and the most common site was labia majora. Most of the cases were non-neoplastic accounting for $85.4 \%$ of cases. Only 6 cases were malignant and all of them were squamous cell carcinoma.

\section{CONCLUSION}

Biopsies are essential for rapid and correct diagnosis of vulval lesions as they are difficult to distinguish on clinical grounds alone due to similar modes of presentation.

In our study, we received a higher proportion of neoplastic lesions as compared to previous studies done in India. The share of neoplastic lesions was very high among post-menopausal women. Most of the malignant cases were of squamous cell carcinoma. These findings may be attributed to chance occurrence due to selective biopsies by the clinician, rising awareness towards female genital cancers or less probably due to rising incidence of neoplasms. Additionally, patients availing health facilities very late in the course of the disease could be a potential cause in the increased incidence of squamous cell carcinoma. This delay in seeking medical help is partly due to the nature and location of lesions associated with socio-cultural stigma along with lack of access to healthcare facilities.

Rarer malignancies were also seen at a higher frequency than has been previously reported. Recalling the fact that the vulval region is formed by close juxta-positioning of the three embryological layers and neurovascular structures, it becomes pertinent that any of these components may be involved in vulval pathology from neural, mesenchymal to epithelial. Our hospital may also have received a higher number of neoplastic cases which may have been referred due to it being a tertiary care centre.

\section{Funding: No funding sources Conflict of interest: None declared Ethical approval: Not required}

\section{REFERENCES}

1. Ozdemir O, Sari ME, Ertugrul FA, Sen E, Ilgin BU, Atalay C. Spectrum of Vulvar Lesions in an Obstetrics and Gynecology Outpatient Clinic. Medic Sci. 4(1):1876-84.

2. Kahramanoglu I, Turan H, Oner YO, Bese T, Ilvan S, Arvas M, et al. A Very Rare Case: HPV-Negative Vulvar Cancer in an Adolescent. Ca Repor Obstet Gynecol. 2018;2018.

3. Sokol AI, Sokol ER. General gynecology: the requisites in obstetrics and gynecology. Elsev Heal Sci. 2007.

4. Foster DC. Vulvar disease. Obstet Gynecol. 2002;100(1):145-63.

5. Doyen J, Demoulin S, Delbecque K, Goffin F, Kridelka F, Delvenne P. Vulvar skin disorders throughout lifetime: about some representative dermatoses. Bio Med Res Int. 2014;2014.

6. Mohan H, Kundu R, Arora K, Punia RS, Huria A. Spectrum of vulvar lesions: a clinicopathologic study of 170 cases. Int J Reprod Contracept Obstet Gynecol. 2014;3(1):175-80.

7. Iyengar $\mathrm{S}$, Acheson $\mathrm{N}$. Premalignant vulval conditions. Obstet Gynaecol Reprod Med. 2008;18(3):60-3.

8. Bowen AR, Vester A, Marsden L, Florell SR, Sharp $\mathrm{H}$, Summers P. The role of vulvar skin biopsy in the evaluation of chronic vulvar pain. Am J Obstet Gynecol. 2008;199(5):467-e1.

9. Kelekci KH, Adamhasan F, Gencdal S, Sayar H, Kelekci S. The impact of the latest classification system of benign vulvar diseases on the management of women with chronic vulvar pruritus. Ind $\mathbf{J}$ Dermatol, Venereol, Leprol. 2011;77(3):294.

10. Fatoohi BY. Collins test in patients with vulvar pruritus. Int J Gynaecol Obstet. 2009;104(1):76.

11. Acheson N, Ganesan R, Chan KK. Premalignant vulvar disorders. Curr Obstet Gynaecol. 2000;10(1):12-7.

12. Del Pino M, Rodriguez-Carunchio L, Ordi J. Pathways of vulvar intraepithelial neoplasia and squamous cell carcinoma. Histopathology 2013;62(1):161-75.

13. Westermann C, Fischer A, Clad A. Treatment of vulvar intraepithelial neoplasia with topical 5\% 
imiquimod cream. Int $\mathbf{J}$ Gynaecol Obstet. 2013;120(3):266-70.

14. Robinson Z, Edey K, Murdoch J. Invasive vulval cancer. Obstet Gynaecol Reprod Med. 2011;21(5):129-36.
15. Judson PL, Habermann EB, Baxter NN. Trends in the incidence of invasive and in situ vulvar carcinoma. Obstet Gynecol. 2006;107:1018-22.

Cite this article as: Bhat R, Kolte S. 5-year experience with vulval lesions in a tertiary care hospital: series of 115 cases. Int J Reprod Contracept Obstet Gynecol 2020;9:5001-5. 